\title{
Determinants for return to work among sickness certified patients in general practice
}

\author{
Anna-Sophia von Celsing ${ }^{1,2^{*}}$, Kurt Svärdsudd ${ }^{1}$, Hans-G Eriksson² ${ }^{2}$ Karin Björkegren ${ }^{1}$, Margaretha Eriksson ${ }^{1}$ \\ and Thorne Wallman ${ }^{1,2}$
}

\begin{abstract}
Background: Long-term sickness absence is one of the main risk factors for permanent exit out of the labour market. Early identification of the condition is essential to facilitate return to work. The aim of this study was to analyse possible determinants of return to work and their relative impact.

Methods: All 943 subjects aged 18 to 63 years, sickness certified at a Primary Health Care Centre in Sweden from 1 January until 31 August 2004, were followed up for three years. Baseline information on sex, age, sick leave diagnosis, employment status, extent of sick leave, and sickness absence during the year before baseline was obtained, as was information on all compensated days of sick leave, disability pension and death during follow-up.

Results: Slightly more than half the subjects were women, mean age was 39 years. Half of the study population returned to work within 14 days after baseline, and after three years only 15 subjects were still on sick leave. In multivariate proportional hazards regression analysis the extent of previous sick leave, age, being on part-time sick leave, and having a psychiatric, musculoskeletal, cardiovascular, nervous disease, digestive system, or injury or poisoning diagnosis decreased the return to work rate, while being employed increased it. Marital status, sex, being born in Sweden, citizenship, and annual salary had no influence. In logistic regression analyses across follow-up time these variables altogether explained $88-90 \%$ of return to work variation.
\end{abstract}

Conclusions: Return to work was positively or negatively associated by a number of variables easily accessible in the GP's office. Track record data in the form of previous sick leave was the most influential variable.

\section{Background}

Disability pension has been shown to be associated with negative health development [1-5]. Long-term sickness absence is one of the main risk factors for permanent exit out of the labour market. There is no generally established definition of long-term sickness absence in the literature, and number of days, regarded as longterm sickness absence, vary considerably between different studies i.e. from $>3$ days to 90 days or more [6,7]. The reason for choosing a specific cut-off level of days can be the availability of sickness absence data [8] or adjustment to the current social insurance legislation [9]. Long-term sickness absence usually begins with recurrent periods of short-term sick leave that tend to

\footnotetext{
* Correspondence: anna-sophia.von.celsing@pubcare.uu.se

'Department of Public Health and Caring Sciences, Family Medicine and Preventive Medicine Section, Uppsala University, Uppsala, Sweden ${ }^{2}$ Centre for Clinical Research Sörmland, Uppsala University, Eskilstuna, Sweden
}

(c) 2012 von Celsing et al.; licensee BioMed Central Ltd. This is an Open Access article distributed under the terms of the

increase in duration, interspersed with shorter and shorter non-sick leave intervals [10]. Long-term sickness absence may also be expressed in terms of return to work, since long-term sickness absence is inversely related to return-to-work, when long-term sickness decreases return to work increases, all things considered.

Early detection of patients at risk for long-term sickness absence may be of importance for identification of individuals in need of rehabilitation measures in order to regain their work ability [11]. A number of potential determinants have been identified such as female sex, old age, low socio-economic status, and previous spells of sick leave [12-15]. Some sick leave diagnoses appear to be more prone to long-term sick leave periods than others, such as musculoskeletal disorders, psychiatric disease, and cardiovascular disorders [1,7,16-24]. Workrelated factors, such as physically heavy work, high work demands, low work control, low job satisfaction, relational problems at the workplace, and a stressful work

\section{(}

distribution, and reproduction in any medium, provided the original work is properly cited. 
situation tend to increase long-term sickness absence $[9,25,26]$ and thereby postpone return to work, as does being unemployed [27] and being on part-time sick leave [28].

All Swedish permanent residents, whether citizens or not, have a unique 12-digit personal identification number (PIN), given at birth or immigration and used in all official documents and registers. The PIN is an excellent and highly reliable tool for record linkage. Moreover, all residents are covered by the National Social Insurance, which includes the right to see a physician of ones own choice and access to hospital care at heavily subsidized rates, to have sickness benefit for income loss in case of reduced work capacity due to injury or disease, and a number of other items. The National Social Insurance is regulated by the National Insurance Act and is managed by the National Social Insurance Agency (SIA), a government agent with offices in all municipalities across the country.

Sick listing is a common and problematic task for general practitioners (GPs) [29-32]. One problem is the assessment as to whether a patient will return to work or not after a period of sick leave. In general practice, there is seldom time during a brief consultation for deep sickness history penetration, or for time-consuming identification of risk factors for long-term sickness absence. However, even when identified the relative impacts of long-term sickness absence determinants on return to work are not well known.

County Councils run the overwhelming part of Swedish medical care. They are responsible for health care within their area; either at County Council operated primary health care centres, at the time of the study the vast majority, or at subcontracted private primary health care centres. However, all centres, whether County Council operated or privately subcontracted, follow the same regulations.

In case of sick leave, patient's self-certification is accepted for an initial period of seven days. After this period a sickness certificate form has to be completed by the patient's physician and sent to the patient's work place. At the time of data collection the employer was responsible for sickness compensation during the first 14 days. If the sickness absence persisted after this time, the sick leave certificate was sent to the local SIA office, which then took responsibility for sickness compensation and for further handling. For unemployed subjects SIA took responsibility for sickness compensation from day 1. Otherwise, the same procedure as for employed subjects was followed.

Information on age, sex, occupational status, sick leave diagnoses, examination results, impaired functions attributable to the disease causing the reduced working capacity, suggested degree of sick leave, and suggestions for various rehabilitation measures to regain work capacity have to be documented in the certificate to enable a decision by SIA as to whether the patient fulfils the criteria for further sickness compensation.

The aim of this study was to analyse possible determinants of return to work and their relative impacts, in order to arrive at a simple model by which return to work might be estimated early in the sick leave process.

\section{Methods \\ Setting}

The study was performed in the city of Eskilstuna, Sweden, at one of the County Council operated primary health care centres, with ten GPs serving a population of approximately 25,000 residents. Eskilstuna is an industrial city with 91,000 residents in 2004, located 110 kilometres west of Stockholm.

\section{Study population}

The study was designed as a three-year prospective cohort study with recruitment from 1 January until $31 \mathrm{Au}-$ gust 2004. During the recruitment period copies of all sickness certificates, whether new or prolongation certificates, issued at the primary health care centre, were obtained. All individuals aged 18 to 63, who were sickness certified by a physician at the centre at any time during the recruitment period, and who were not already included in a medical or vocational rehabilitation programme, were included, 482 women and 461 men, altogether 943 subjects.

Information on sex, attained age at the baseline examination, being born in Sweden, citizenship, marital status (classified as never married, married, divorced or widowed), occupational status (being employed or not), salary at baseline expressed in Euro, sick leave diagnosis, and degree of sick leave $(25 \%, 50 \%, 75 \%$ or $100 \%)$ was obtained from the local SIA office. Information on sickness absence during the year preceding the baseline examination and the three years following baseline was obtained from the SIA database, and also from the primary health care medical records in order to have valid information on sick leave during the first 14 days.

Outcome in this study was conclusion of the sick certification period in effect at baseline, in other words return to work, although some subjects did not have a work to return to. Data on all certified sick leave periods for the three years following baseline, including first and last day of each sickness spell, type of sickness benefit (compensation for sickness or rehabilitation), sick leave diagnosis, degree of sick leave, and whether a disability pension was granted during follow-up, was obtained from the SIA national database. Information on vital status was obtained from the National Cause of Death Register, providing date of death for those who died $(\mathrm{n}=$ 
6). The sick leave diagnoses were coded according to the International Classification of Diseases (ICD-10) [33]. The Regional Ethics Review Board, Stockholm, Sweden, approved the study.

\section{Statistical methods}

Data were analysed with the SAS software, version 9.2. There was no missing data. The three-year sick leave follow-up data were converted into a day-by day matrix starting with variable day 0 (baseline day) and ending with variable day 1095 (end of follow-up), each variable measuring whether the subject was on sick leave $(=1)$ or not $(=0)$ on that day.

Based on this matrix a return-to-work variable was computed. For each sick spell the following two returnto-work criteria were applied. Criterion 1: the sick spell was followed by a sick leave free interval of more than 28 days, regardless of the length of any following sick spell. Criterion 2: the sick spell was followed by a sick leave free interval of more than 7 days, and that interval was longer than the next sick spell. When at least one of the criteria was satisfied, return to work was presumed to have occurred on the first non-sick leave day. If none of the criteria were satisfied at end of follow up no return-to-work was presumed to have occurred.

Follow-up time from baseline to return to work or end of follow-up was measured as number of days from baseline. Determinants for return to work were tested with proportional hazards regression technique (Cox's analysis), using the SAS procedure 'Phreg', with return to work and the day when this occurred as outcome, and age at baseline, sex, number of days of sick leave during the year preceding baseline, whether on full time or part time sick leave, marital status, whether employed, born in Sweden, being a Swedish citizen or not, salary during the last year, and sick leave diagnosis included as potential determinants. The procedure provides hazards ratios (HR), 95\% confidence intervals (95\%CI), and Wald's chisquare, the latter, being the test parameter and computed with one degree of freedom for all variables regardless of grading, and therefore used as measure of determinant impact on outcome.

The analyses were performed in two steps. First, orienting bivariate analyses were performed, one for each potential determinant, followed by multivariate analyses. In the latter, variables with mutually exclusive responses, such as marital status and sick leave diagnoses, were analysed with dummy variables. For marital status, being married, which had the hazard ratio (HR) closest to 1, was chosen as reference for the effect of marital status, and regarding sick leave diagnoses, respiratory system disease (ICD-10 code J, (in most cases upper respiratory tract infections) had the same characteristics and was used as reference for the effects of the diagnoses. To arrive at interpretable HRs, number of days of sick leave during the past year was recomputed as number of weeks, and age as five-year age groups.

The analyses were performed straightforwardly with sex as determinant as well as stratified for sex. In the latter, the results for women and men were similar. For this reason only results from the former type of analysis are shown.

The content of Figure 1 was computed with proportional hazards regression technique using the same multivariate analysis model as for the multivariate analyses. Data on the effects on return-to-work of age, sick leave days during the year before baseline, having a psychiatric diagnosis, a having a respiratory disease variable was obtained from the analysis model. Regarding age data for persons aged $20,30,40,50$, or 60 years, and for sick leave during the year before baseline days $0,28,90$, and 180 were obtained from the model. Regarding the diagnoses data on those with a diagnosis and those with no such diagnosis were obtained from the analysis model.

The degree of explanation, i.e. how well the determinants could explain return to work, was measured with nominal logistic regression across the follow-up period during the first $7,14,28,90,180,270,365,455$, and 545 days, using Concordance index (C), an estimate of the area under the receiver operating curve characteristic (ROC) curve, and a standard option in SAS 'Logist' procedure, and with the same variable set up as in the proportional hazards regression analysis model [34]. All tests were two-tailed and the significance level was set at $\mathrm{p}<0.05$.

\section{Results}

\section{Characteristics of the study population}

Slightly more than half the subjects were women, mean and median age were 39 years, more than $75 \%$ were employed, more than 93\% were Swedish citizens, $44 \%$ were never married and somewhat more than one third were married, mean annual income was 22,000€, mean number of days of sick leave during the year preceding baseline was 51, and the vast majority were on full-time sick leave, Table 1 . The most common sickness certification diagnoses in rank order were musculoskeletal disease, psychiatric disease, and respiratory system disease.

At baseline all subjects were on sick leave. Among both men and women $50 \%$ of the subjects had returned to work within 14 days, $75 \%$ of the men within 55 days and $75 \%$ of the women within 80 days. At end of follow-up $6(1.3 \%)$ men and $9(1.9 \%)$ women were still on sick leave.

\section{Potential determinants of return to work}

The effects of potential determinants for return to work are shown in Table 2 . In bivariate analyses previous sick 


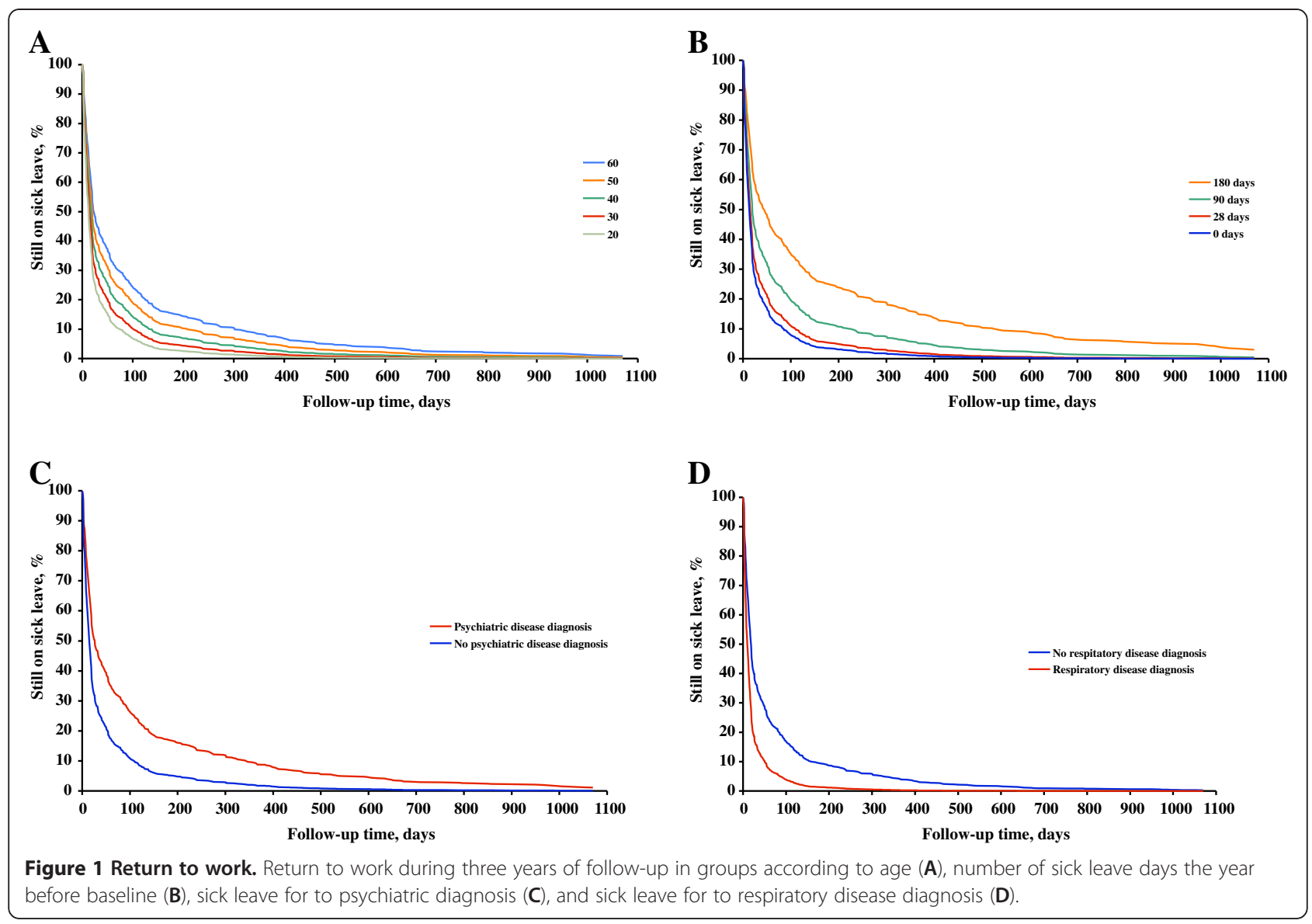

leave, age, present part-time sick leave, being divorced, being born in Sweden, and being a Swedish citizen all decreased the probability of return to work, while male sex, being never married, and being employed increased it. Annual salary had no significant influence.

Among the diagnoses some positively and other negatively associated with the probability of return to work. The most influential ones were respiratory system disease, infectious disease, eye or ear disease, and unspecific symptoms and signs that increased probability, while psychiatric and musculoskeletal disorders decreased the probability of return to work.

In multivariate analysis previous sick leave, age, present part-time sick leave, and being employed kept their significance for return to work, while marital status, male sex, being born in Sweden, citizenship, and annual salary did not. Among the diagnoses psychiatric and musculoskeletal disorders, cardiovascular diseases, unspecific symptoms and signs, nervous system disease, digestive system disease, injury and poisoning, and miscellaneous diseases were significantly associated with decreased probability for return to work.

The effects over time of age, previous sick leave, having a psychiatric diagnosis and having a respiratory system diagnosis are shown in Figure 1. For each 10 years of age from age 30 the return to work was slower than in the previous decade. On the 100th day $7 \%$ of the 20 -year olds were still on sick leave versus $25 \%$ of the 60 -year old. Among those who had no sick leave days during the last year $8 \%$ were still on sick leave on the 100th day versus $35 \%$ of those with 180 sick leave days during the last year. Among those with no psychiatric diagnosis $11 \%$ were on sick leave on the 100th day versus $27 \%$ among those with such a diagnosis, and finally among those with an upper respiratory tract diagnosis $4 \%$ were still on sick leave on the 100th day as compared with $17 \%$ among those with other diagnoses.

\section{Degree of explanation}

The degree of explanation across the first one and a half year of follow-up is shown in Figure 2. Using only the most influential variable, sick leave due to psychiatric diagnosis, the degree of explanation would be approximately $55 \%$ throughout the follow-up period. Including also the previous sick leave track record increased the degree of explanation to approximately $85 \%$, and by including all other significant determinants degree of explanation approached 88\% -90\%. 
Table 1 Characteristics of the study population

\begin{tabular}{|c|c|c|c|c|}
\hline & \multicolumn{2}{|c|}{ Women } & \multicolumn{2}{|c|}{ Men } \\
\hline & $\bar{n}$ & Mean (SD) or\% & $\mathrm{n}$ & Mean (SD) or\% \\
\hline \multicolumn{5}{|l|}{ Age, years } \\
\hline Mean & 482 & $39.1(12.04)$ & 461 & $39.2(11.66)$ \\
\hline Inter-quartile range & & $29-49$ & & $30-48$ \\
\hline Employed,\% & 365 & 75.7 & 356 & 77.2 \\
\hline Born in Sweden,\% & 389 & 80.7 & 342 & 74.2 \\
\hline Swedish citizen, $\%$ & 454 & 94.2 & 429 & 93.1 \\
\hline \multicolumn{5}{|l|}{ Marital status, $\%$} \\
\hline Never married & 195 & 40.5 & 218 & 47.3 \\
\hline Married or cohabiting & 183 & 38.0 & 162 & 35.1 \\
\hline Divorced & 90 & 18.7 & 79 & 17.1 \\
\hline Widowed & 12 & 2.5 & 2 & 0.4 \\
\hline \multicolumn{5}{|l|}{ Annual salary at baseline, $€$} \\
\hline Mean & 373 & $20,127(5,386)$ & 342 & $24,241(8,195)$ \\
\hline Inter-quartile range & & $17,333-23,333$ & & $20,000-26,667$ \\
\hline \multicolumn{5}{|l|}{ Sick leave before baseline, days } \\
\hline Mean & & $55.1(105.82)$ & & $48.8(94.69)$ \\
\hline Inter-quartile range & & $0-49$ & & $0-35$ \\
\hline Full-time sick leave at baseline & 431 & 89.4 & 430 & 93.3 \\
\hline \multicolumn{5}{|l|}{ Sick leave diagnoses, $\%$} \\
\hline Musculoskeletal disease & 150 & 31.1 & 152 & 33.0 \\
\hline Psychiatric disease & 131 & 27.2 & 90 & 19.5 \\
\hline Respiratory disease & 88 & 18.3 & 70 & 15.2 \\
\hline Injury, poisoning & 17 & 3.5 & 34 & 7.4 \\
\hline Symptoms and signs & 33 & 6.9 & 31 & 6.7 \\
\hline Infectious-parasite disease & 12 & 2.5 & 20 & 4.3 \\
\hline Dermatology disease & 9 & 1.9 & 9 & 2.0 \\
\hline Cardiovascular disease & 8 & 1.7 & 10 & 2.2 \\
\hline Genitourinary system disease & 7 & 1.5 & 8 & 1.7 \\
\hline Digestive system disease & 5 & 1.0 & 13 & 2.8 \\
\hline Eye or ear disease & 5 & 1.0 & 6 & 1.3 \\
\hline Nervous system disease & 5 & 1.0 & 5 & 1.1 \\
\hline Endocrine-metabolic disease & 4 & 0.8 & 3 & 0.7 \\
\hline Blood disease & 3 & 0.6 & 1 & 0.2 \\
\hline Pregnancy, childbirth & 1 & 0.2 & 0 & - \\
\hline Miscellaneous & 4 & 0.8 & 9 & 2.0 \\
\hline
\end{tabular}

Baseline characteristics of the study population.

\section{Discussion}

The degree of explanation for all variables combined was slightly short of $90 \%$, indicating that the major influencing variables were included in the analysis model. The two most influential variables, sick leave because of psychiatric disease and sick leave track record together explained approximately $85 \%$ of return to work. The determinants of return to work in this study in rank order were sick leave because of psychiatric disease, sick leave track record, sick leave because of musculoskeletal disease, cardiovascular disease, symptoms and signs, nervous system disease, digestive system disease, injuries and poisoning, and age, being employed, extent of sick leave and miscellaneous diseases. The latter four variables had only marginal effects. 
Table 2 Return to work determinants

\begin{tabular}{|c|c|c|c|c|c|c|c|c|}
\hline & \multicolumn{4}{|c|}{ Bivariate analysis } & \multicolumn{4}{|c|}{ Multivariate analysis } \\
\hline & $\mathrm{HR}$ & $95 \% \mathrm{Cl}$ & Wald's $X^{2}$ & $\mathrm{p}$ & $\mathrm{HR}$ & $95 \% \mathrm{Cl}$ & Wald's $x^{2}$ & $p$ \\
\hline Previous sick leave by week & 0.97 & $0.96-0.97$ & 150.5 & $<0.0001$ & 0.97 & $0.97-0.98$ & 92.0 & $<0.0001$ \\
\hline Age by 5-year groups & 0.91 & $0.88-0.94$ & 38.6 & $<0.0001$ & 0.95 & $0.92-0.99$ & 6.9 & $<0.01$ \\
\hline Employed & 1.38 & $1.18-1.62$ & 16.3 & $<0.0001$ & 1.28 & $1.02-1.59$ & 4.7 & $<0.05$ \\
\hline Part-time sick leave & 0.57 & $0.45-0.72$ & 22.4 & $<0.0001$ & 0.75 & $0.58-0.98$ & 4.5 & $<0.05$ \\
\hline \multicolumn{9}{|l|}{ Marital status } \\
\hline married & 1.10 & $0.96-1.25$ & 1.8 & 0.17 & 1.00 & reference & - & - \\
\hline never married & 1.16 & $1.02-1.32$ & 5.1 & $<0.05$ & & & 2.3 & 0.13 \\
\hline divorced & 0.74 & $0.62-0.87$ & 12.7 & $<0.0005$ & & & 0.9 & 0.33 \\
\hline widowed & 0.61 & $0.35-1.06$ & 3.1 & 0.08 & & & 0.3 & 0.56 \\
\hline Born in Sweden & 0.82 & $0.70-0.95$ & 6.6 & $<0.05$ & & & 1.5 & 0.22 \\
\hline Male sex & 1.16 & $1.02-1.32$ & 4.7 & $<0.05$ & & & 1.3 & 0.26 \\
\hline Annual salary by $10,000 €$ & 0.99 & $0.90-1.08$ & 0.1 & 0.80 & & & 0.7 & 0.39 \\
\hline Swedish citizenship & 0.77 & $0.59-0.99$ & 4.0 & $<0.05$ & & & 0.03 & 0.85 \\
\hline \multicolumn{9}{|l|}{ Diagnosis } \\
\hline Respiratory disease & 2.36 & $1.97-2.82$ & 88.3 & $<0.0001$ & 1.00 & reference & - & - \\
\hline Psychiatric disease & 0.70 & $0.60-0.82$ & 20.6 & $<0.0001$ & 0.31 & $0.25-0.40$ & 94.9 & $<0.0001$ \\
\hline Musculoskeletal disease & 0.79 & $0.69-0.91$ & 11.2 & $<0.001$ & 0.41 & $0.33-0.51$ & 67.6 & $<0.0001$ \\
\hline Cardiovascular disease & 0.72 & $0.45-1.14$ & 1.9 & 0.16 & 0.30 & $0.17-0.52$ & 18.4 & $<0.0001$ \\
\hline Symptoms and signs & 1.33 & $1.03-1.71$ & 4.7 & $<0.05$ & 0.53 & $0.38-0.75$ & 12.8 & $<0.0005$ \\
\hline Nervous system disease & 0.68 & $0.35-1.32$ & 1.3 & 0.26 & 0.26 & $0.12-0.57$ & 11.6 & $<0.001$ \\
\hline Digestive system disease & 0.82 & $0.51-1.32$ & 0.7 & 0.41 & 0.41 & $0.24-0.71$ & 10.1 & $<0.005$ \\
\hline Injury, poisoning & 1.12 & $0.84-1.49$ & 0.6 & 0.44 & 0.56 & $0.39-0.80$ & 9.9 & $<0.005$ \\
\hline Miscellaneous & 1.02 & $0.59-1.77$ & 0 & 0.93 & 0.48 & $0.23-0.98$ & 4.1 & $<0.05$ \\
\hline Endocrine-metabolic disease & 1.29 & $0.61-2.71$ & 0.4 & 0.50 & & & 3.0 & 0.08 \\
\hline Eye or ear disease & 1.83 & $1.01-3.31$ & 3.9 & $<0.05$ & & & 2.8 & 0.09 \\
\hline Infectious-parasite disease & 1.62 & $1.14-2.31$ & 7.2 & $<0.001$ & & & 2.2 & 0.14 \\
\hline Genitourinary system disease & 1.21 & $0.73-2.02$ & 0.6 & 0.46 & & & 1.5 & 0.22 \\
\hline Blood disease & 0.72 & $0.27-1.91$ & 0.4 & 0.50 & & & 1.0 & 0.32 \\
\hline Dermatology disease & 1.63 & $1.02-2.61$ & 4.2 & $<0.05$ & & & 0.6 & 0.43 \\
\hline Pregnancy, childbirth & 5.53 & $0.77-39.52$ & 2.9 & 0.09 & & & - & - \\
\hline
\end{tabular}

Potential determinants of return to work within the next 1095 days.

Return to work was in this study defined as termination of the sick leave period according to the criteria used, even though all study participants may not have had a work to go back to. We know which of the participants that were out of a job at baseline, but we do not know the situation at the time when the sick period was terminated. They may have gone back to work, or been granted a disability pension, or been granted social welfare, or been able to support themselves in other ways. Return to work should therefore in this context be interpreted as leaving the sick leave status.

The effects on long-term sickness absence (or return to work) of female sex, increasing age and unemployment have previously been reported in other studies [10,14]. In the present study sex was moderately influential in bivariate with a Wald's chi-square of 4.7 as compared to previous sick leave that had a Wald's chi-square of 150.5. It is therefore not surprising that sex had no significant influence in multivariate analysis. It was simply competed out by variables with much stronger impact. Performing the analyses with sex as a determinant or stratified according to sex made no difference. The effects of some of the sick leave diagnoses, especially psychiatric disease and musculoskeletal disorders that tend to prolong sick leave, have previously been shown $[16,18,19,21,24,35,36]$. In this study a number of other diagnoses proved to be 


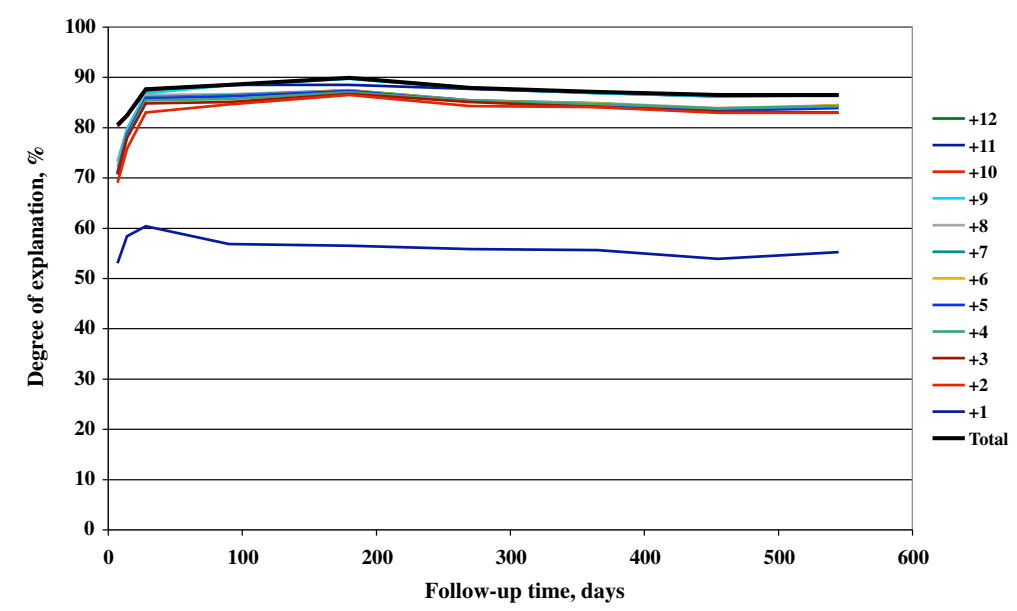

Figure 2 Degree of explanation. Cumulative degree of explanation of twelve significant return-to-work determinants, given in ranking order according to importance (Wald's $\times 2$ ) and measured on days 7, 14, 28, 90, 180, 270, 365, 455, and 545. 1 = sick certified for psychiatric disease, 2 = number of sick leave days the year before baseline, 3 = sick certified for musculo-skeletal disease, $4=$ sick certified for cardiovascular disease, $5=$ sick certified due to unspecified symptoms or signs, $6=$ sick certified for nervous system disease, $7=$ sick certified for digestive system disease, $8=$ sick certified for injury or poisoning, $9=$ age at baseline, $10=$ employed, $11=$ extent of sick leave, $12=$ sick certified for miscellaneous disease.

significant determinants, some facilitating, others delaying return to work, a novel finding, not reported before.

In the present study information on previous sick leave, or sick leave track record, was one of the most informative factors for predicting return to work. The possible use of administrative sickness absence data as a risk marker of future sickness absence and disability pension was demonstrated in a Danish study [37]. These results have been confirmed in Dutch and British studies $[38,39]$. Previous sick leave as indicator for chronic health problems was shown in a large-scale cohort study [40]. In 1995, Marmot in a study investigating the relationship between self reported health status and sickness absence, found a strong association between ill health and sickness absence, particularly for longer spells [9]. Moreover, in a previous publication from this project previous sick leave, or sick leave track record, was closely associated with being granted a disability pension [10].

Are there more determinants for return-to-work, not measured in this study? Yes, probably, but these potential determinants are unlikely to change the main results of this study. Even if such a determinant has a strong impact on return-to-work in bivariate analysis, the potential impact in the multivariate analysis model used in this study is at the most $10 \%$, since the variables included explained $90 \%$ of return-to-work. This means that potential determinants not included in the study most probably have a marginal effect as compared to variables included in the present study.

In the UK, GPs often consider the judging of whether or not a patient is fit for work, to be a "highly complex process, involving reconsideration, uncertainty, and a number of stages and types of deliberation" [41]. In a survey among Swedish physicians in two counties [42] a larger proportion of physicians at orthopaedic clinics and, in particular, at primary health care centres, experienced more sick-listing problems than physicians at other clinics. Engblom et al. [43] identified categories of specific difficulties GPs experience in their clinical practice when face-to-face with the patient.

Sick-listing difficulties appear to be shared by physicians in several countries [44-47]. Reiso et al. [48] raised the question of how well a GP may predict return to work, and found GPs' predictions for return to work highly accurate for short-term episodes but less so for more long-term ones. In a Norwegian study, sick-listed individuals predicted their length of sick leave more accurately than professionals [49].

The strengths of this study include that the study population was large enough for the purpose of the study, that it was based on all patients passing through the 'time window' of data collection, making it equivalent to a random patient sample. The exposure and outcome data used in the analyses were obtained from the official SIA sick leave database, and from medical records regarding the first two weeks of sick leave. Data was complete with no data loss.

One possible limitation of the study could be the choice of the six determinants (counting diagnoses as one determinant), as other variables might serve the same purpose for screening individuals at risk for longterm sickness absence. However, the variables chosen have been shown to be long-term sickness absence 
determinants in previous studies [14], and five of the six are readily available to the GP when issuing a sickness certificate. The sixth variable, previous periods of sick leave, is usually accessible information in the primary health care records. At any rate, the variables chosen proved to be quite sufficient for the prediction purpose. The $10 \%$ unexplained return to work proportion indicates that no major determinant was overlooked.

The implications of the result of the present study might be that the existing difficulties in assessing the possibilities for return to work are relatively easily overcome, since the number of variables to take into account is limited. As shown in Figure 2, access to all six variables provided an excellent degree of explanation. However, access to only the two most powerful variables, sick leave diagnosis and sick leave track record during the past year, yielded an explanation of return to work of approximately $85 \%$ as early as during the first month. Sick leave diagnosis is always available. Similarly, sick leave track record is readily available in countries with a GP gatekeeping system, while GPs in other health care systems may have to rely on information given by patients. A better availability for the GP of sick leave track record from the stakeholders should improve the possibilities to arrive at a reasonably precise sick leave prognosis.

\section{Conclusions}

A number of variables were associated with return to work. Track record data in the form of previous sick leave was the most influential variable. Together the determinants explained $88-90 \%$ of the return to work variation during follow-up. However, the two most important determinants together explained approximately $85 \%$ of the return to work. It might therefore be possible to assess the possibilities of return to work based on data available at the time of sick certification, thereby avoiding long-term sickness absence.

\section{Competing interests}

The authors declare that they have no competing interests.

\section{Authors' contributions}

ASvC was responsible for the conception and design of the study and data collection. HE compiled the database. HE and KS analysed the data. ASvC, TW and KS drafted the manuscript. All authors participated in the interpretation of the results, the revision of the manuscript, and the approval of the final manuscript version.

\footnotetext{
Acknowledgements

The study was supported by grants from Samordningsförbundet RAR Sörmland,

Centre for Clinical Research Sörmland, Uppsala University, Eskilstuna, Sörmland County Council, and Uppsala University, Sweden.
}

Received: 6 June 2012 Accepted: 23 November 2012

Published: 14 December 2012

\section{References}

1. Gjesdal S, Haug K, Ringdal P, Maeland JG, Hagberg J, Roraas T, Vollset SE, Alexanderson K: Sickness absence with musculoskeletal or mental diagnoses, transition into disability pension and all-cause mortality: a 9-year prospective cohort study. Scand J Public Health 2009, 37(4):387-394.

2. Gjesdal S, Svedberg P, Hagberg J, Alexanderson K: Mortality among disability pensioners in Norway and Sweden 1990-96: comparative prospective cohort study. Scand J Public Health 2009, 37(2):168-175.

3. Gjesdal S, Ringdal PR, Haug K, Maeland JG: Predictors of disability pension in long-term sickness absence: results from a population-based and prospective study in Norway 1994-1999. Eur J Public Health 2004, 14(4):398-405.

4. Wallman $T$, Wedel $H$, Johansson $S$, Rosengren A, Eriksson $H$, Welin L, Svardsudd $K$ : The prognosis for individuals on disability retirement. An 18-year mortality follow-up study of 6887 men and women sampled from the general population. BMC Publ Health 2006, 6:103.

5. Kivimaki M, Forma P, Wikstrom J, Halmeenmaki T, Pentti J, Elovainio M, Vahtera J: Sickness absence as a risk marker of future disability pension: the 10-town study. J Epidemiol Community Health 2004, 58(8):710-711.

6. Vahtera J, Pentti J, Kivimaki M: Sickness absence as a predictor of mortality among male and female employees. J Epidemiol Community Health 2004, 58(4):321-326.

7. Vaez M, Rylander G, Nygren A, Asberg M, Alexanderson K: Sickness absence and disability pension in a cohort of employees initially on long-term sick leave due to psychiatric disorders in Sweden. Soc Psychiatry Psychiatr Epidemiol 2007, 42(5):381-388.

8. Lidwall U: Long-term sickness absentees-demography, work, occupation, diagnosis, eligibility to compensation and return to work 2003, 2005 and 2006. Stockholm: Social Insurance Agency; 2007.

9. Marmot M, Feeney A, Shipley M, North F, Syme SL: Sickness absence as a measure of health status and functioning: from the UK Whitehall II study. J Epidemiol Community Health 1995, 49(2):124-130.

10. Wallman T, Wedel H, Palmer E, Rosengren A, Johansson S, Eriksson H, Svardsudd K: Sick-leave track record and other potential predictors of a disability pension. A population based study of 8,218 men and women followed for 16 years. BMC Publ Health 2009, 9:104.

11. Suoyrjo H, Oksanen T, Hinkka K, Kivimaki M, Klaukka T, Pentti J, Vahtera J: The effectiveness of vocationally oriented multidisciplinary intervention on sickness absence and early retirement among employees at risk: an observational study. Occup Environ Med 2009, 66(4):235-242.

12. Gjesdal S, Bratberg E: The role of gender in long-term sickness absence and transition to permanent disability benefits. Results from a multiregister based, prospective study in Norway 1990-1995. Eur J Public Health 2002, 12(3):180-186.

13. Lidwall U, Bergendorff S, Voss M, Marklund S: Long-term sickness absence: changes in risk factors and the population at risk. Int J Occup Med Environ Health 2009, 22(2):157-168.

14. Allebeck P, Mastekaasa A: Swedish Council on Technology Assessment in Health Care (SBU). Chapter 5. Risk factors for sick leave - general studies. Scand J Public Health Suppl 2004, 63:49-108.

15. Karlsson N, Borg K, Carstensen J, Hensing G, Alexanderson K: Risk of disability pension in relation to gender and age in a Swedish county; a 12-year population based, prospective cohort study. Work 2006, 27(2):173-179.

16. Du Bois M, Szpalski M, Donceel P: Patients at risk for long-term sick leave because of low back pain. Spine J 2009, 9(5):350-359.

17. Lotters F, Burdorf A: Prognostic factors for duration of sickness absence due to musculoskeletal disorders. Clin J Pain 2006, 22(2):212-221.

18. Alexanderson KA, Borg KE, Hensing GK: Sickness absence with low-back, shoulder, or neck diagnoses: an 11-year follow-up regarding gender differences in sickness absence and disability pension. Work 2005, 25(2): 115-124

19. Bratberg E, Gjesdal S, Maeland JG: Sickness absence with psychiatric diagnoses: individual and contextual predictors of permanent disability. Health Place 2009, 15(1):308-314.

20. Koopmans PC, Roelen CA, Bultmann U, Hoedeman R, van der Klink J, Groothoff JW: Gender and age differences in the recurrence of sickness absence due to common mental disorders: a longitudinal study. BMC Publ Health 2010, 10:426. 
21. Kivimaki M, Ferrie JE, Hagberg J, Head J, Westerlund H, Vahtera J, Alexanderson K: Diagnosis-specific sick leave as a risk marker for disability pension in a Swedish population. J Epidemiol Community Health 2007, 61(10):915-920.

22. Morken T, Riise T, Moen B, Hauge SH, Holien S, Langedrag A, Pedersen S, Saue IL, Seljebo GM, Thoppil V: Low back pain and widespread pain predict sickness absence among industrial workers. BMC Musculoskelet Disord 2003, 4:21.

23. Hensing G, Wahlstrom R: Swedish Council on Technology Assessment in Health Care (SBU). Chapter 7. Sickness absence and psychiatric disorders. Scand J Public Health Suppl 2004, 63:152-180.

24. Gjesdal S, Bratberg E: Diagnosis and duration of sickness absence as predictors for disability pension: results from a three-year, multi-register based* and prospective study. Scand J Public Health 2003, 31(4):246-254.

25. Hanebuth D, Meinel M, Fischer JE: Health-related quality of life, psychosocial work conditions, and absenteeism in an industrial sample of blue- and white-collar employees: a comparison of potential predictors. J Occup Environ Med 2006, 48(1):28-37.

26. Hultin $\mathrm{H}$, Hallqvist J, Alexanderson K, Johansson G, Lindholm C, Lundberg I, Moller J: Work-related psychosocial events as triggers of sick leave - results from a Swedish case-crossover study. BMC Publ Health 2011, 11:175.

27. Askildsen JE, Bratberg E, Nilsen OA: Unemployment, labor force composition and sickness absence: a panel data study. Health Econ 2005, 14(11):1087-1101.

28. Viikari-Juntura E, Kausto J, Shiri R, Kaila-Kangas L, Takala EP, Karppinen J, Miranda H, Luukkonen R, Martimo KP: Return to work after early part-time sick leave due to musculoskeletal disorders: a randomized controlled trial. Scand J Work Environ Health 2012, 38:134-143.

29. Englund $L$, Svardsudd $K$ : Sick-listing habits among general practitioners in a Swedish county. Scand J Prim Health Care 2000, 18(2):81-86.

30. Arrelov B, Alexanderson K, Hagberg J, Lofgren A, Nilsson G, Ponzer S: Dealing with sickness certification - a survey of problems and strategies among general practitioners and orthopaedic surgeons. BMC Publ Health 2007, 7:273.

31. Lofgren A, Hagberg J, Arrelov B, Ponzer S, Alexanderson K: Frequency and nature of problems associated with sickness certification tasks: a crosssectional questionnaire study of 5455 physicians. Scand J Prim Health Care 2007, 25(3):178-185.

32. Swartling M, Peterson S, Wahlstrom R: Views on sick-listing practice among Swedish General Practitioners-a phenomenographic study. BMC Fam Pract 2007, 8:44.

33. WHO: International Classification of Diseases (ICD-10). In Edited by Welfare TNBoHa. 1997.

34. Hanley JA, McNeil BJ: The meaning and use of the area under a receiver operating characteristic (ROC) curve. Radiology 1982, 143(1):29-36.

35. Ferrie JE, Vahtera J, Kivimaki M, Westerlund H, Melchior M, Alexanderson K, Head J, Chevalier A, Leclerc A, Zins M, et al: Diagnosis-specific sickness absence and all-cause mortality in the GAZEL study. J Epidemiol Community Health 2009, 63(1):50-55.

36. Bergstrom $G$, Bodin $L$, Bertilsson $H$, Jensen IB: Risk factors for new episodes of sick leave due to neck or back pain in a working population. A prospective study with an 18-month and a three-year follow-up. Occup Environ Med 2007, 64(4):279-287.

37. Lund T, Kivimaki M, Labriola M, Villadsen E, Christensen KB: Using administrative sickness absence data as a marker of future disability pension: the prospective DREAM study of Danish private sector employees. Occup Environ Med 2008, 65(1):28-31.

38. Roelen CA, Koopmans PC, Schreuder JA, Anema JR, van der Beek AJ: The history of registered sickness absence predicts future sickness absence. Occup Med (Lond) 2011, 61(2):96-101.

39. Whittaker W, Sutton M, Maxwell M, Munoz-Arroyo R, Macdonald S, Power A, Smith M, Wilson P, Morrison J: Predicting which people with psychosocial distress are at risk of becoming dependent on state benefits: analysis of routinely available data. BMJ 2010, 341:c3838.

40. Vahtera J, Westerlund H, Ferrie JE, Head J, Melchior M, Singh-Manoux A, Zins M, Goldberg M, Alexanderson K, Kivimaki M: All-cause and diagnosisspecific sickness absence as a predictor of sustained suboptimal health: a 14-year follow-up in the GAZEL cohort. J Epidemiol Community Health 2010, 64(4):311-317.

41. Hiscock J, Ritchie J: The role of GPs in sickness certification. 2001.
42. Swartling MS, Hagberg J, Alexanderson K, Wahlstrom RA: Sick-listing as a psychosocial work problem: a survey of 3997 Swedish physicians. J Occup Rehabil 2007, 17(3):398-408.

43. Engblom M, Alexanderson K, Englund L, Norrmen G, Rudebeck CE: When physicians get stuck in sick-listing consultations: a qualitative study of categories of sick-listing dilemmas. Work 2010, 35(2):137-142.

44. Reiso H, Nygard JF, Brage S, Gulbrandsen P, Tellnes G: Work ability assessed by patients and their GPs in new episodes of sickness certification. Fam Pract 2000, 17(2):139-144

45. Gulbrandsen P, Hofoss D, Nylenna M, Saltyte-Benth J, Aasland OG: General practitioners' relationship to sickness certification. Scand J Prim Health Care 2007, 25(1):20-26.

46. Wynne-Jones G, Mallen CD, Main CJ, Dunn KM: Sickness certification and the GP: what really happens in practice? Fam Pract 2010, 27(3):344-350.

47. Hussey S, Hoddinott P, Wilson P, Dowell J, Barbour R: Sickness certification system in the United Kingdom: qualitative study of views of general practitioners in Scotland. BMJ 2004, 328(7431):88.

48. Reiso H, Gulbrandsen P, Brage S: Doctors' prediction of certified sickness absence. Fam Pract 2004, 21(2):192-198.

49. Fleten $\mathrm{N}$, Johnsen $\mathrm{R}$, Forde $\mathrm{OH}$ : Length of sick leave - why not ask the sick-listed? Sick-listed individuals predict their length of sick leave more accurately than professionals. BMC Publ Health 2004, 4:46.

doi:10.1186/1471-2458-12-1077

Cite this article as: von Celsing et al:: Determinants for return to work among sickness certified patients in general practice. BMC Public Health 2012 12:1077.

\section{Submit your next manuscript to BioMed Central and take full advantage of:}

- Convenient online submission

- Thorough peer review

- No space constraints or color figure charges

- Immediate publication on acceptance

- Inclusion in PubMed, CAS, Scopus and Google Scholar

- Research which is freely available for redistribution 